\title{
Avaliação e proposta de monitoramento do estado de conservação de ambiente recifal costeiro do Estado da Paraíba, Brasil: contribuições para gestão ambiental
}

\section{Daniel Silva Lula Leite ${ }^{1}$, George Emmanuel Cavalcanti de Miranda $^{2}$}

${ }^{1}$ Programa de Pós-Graduação em Desenvolvimento e Meio Ambiente. Centro de Ciências Exatas e da Natureza. Universidade Federal da Paraíba. Campus I. João Pessoa-PB, Brasil (CEP 58051-900). E-mail: dan_jpb@hotmail.com.

${ }^{2}$ Departamento de Sistemática e Ecologia. Centro de Ciências Exatas e da Natureza. Universidade Federal da Paraíba. Campus I. João Pessoa-PB, Brasil (CEP 58051-900).

Resumo. A urbanização nas zonas costeiras torna necessário avaliar o impacto antrópico sobre os ecossistemas associados. 0 objetivo deste trabalho foi analisar temporalmente a dinâmica de populações de macroalgas com potencial bioindicador, estabelecendo-as como ferramenta para avaliação da saúde ambiental. Foi amostrado o ambiente recifal intertidal da Praia de Formosa, no Município de Cabedelo, Estado da Paraíba, Nordeste do Brasil, durante intervalos trimestrais de agosto/2013 a novembro/2014. A variação temporal da frequência de ocorrência $\left(\mathrm{F}^{\prime}\right)$ das populações macrofitobênticas foi avaliada pela análise de variância (One-Way Anova) com teste Post-Hoc de Tukey. A influência das variáveis ambientais sobre $F^{\prime}$ foi avaliada pela Correlação Linear de Pearson e pela PERMANOVA. A análise da qualidade ambiental e a proposta de biomonitoramento basearam-se no Grupo 1, formado por espécies perenes e/ou raras com maiores valores ao longo do Componente Principal 1 (CP1) da Análise de Componentes Principais (ACP), e Grupo 2, formado por espécies com comportamento errático com menores valores ao longo do CP1 da ACP. Foram encontradas 33 espécies macrofitobênticas. A frequência de ocorrência apresentou variação temporal, porém não influenciada pelo conjunto de variáveis ambientais. Phyllodictyon anastomosans, Gelidiella acerosa e Gelidium corneum compuseram o Grupo 1, com Dictyopteris delicatula, Canistrocarpus cervicornis e Hypnea spinella formando o Grupo 2. 0 Grupo 2 apresentou correlação positiva com a temperatura, alcançando as máximas frequências nos períodos mais quentes, mas esse fator isolado não é capaz de explicar a distribuição errática das espécies. A ocorrência de espécies bioindicadoras de eutrofização foi considerada natural, fato que, aliado à alta frequência de espécies bioindicadoras de qualidade ambiental, sugerem que o Recife de Formosa não sofre impactos antrópicos significativos. 0 desaparecimento de
Recebido: $04 / 06 / 2018$

Aceito:

$29 / 10 / 2018$

Publicado:

$31 / 12 / 2018$

Acesso aberto

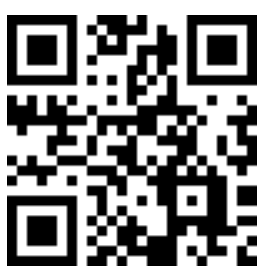

ORCID

(1) 0000-0001-9104-7418 Daniel Silva Lula Leite

D 0000-0002-8975-1067 George Emmanuel Cavalcanti de Miranda 
espécies perenes ou crescimento populacional significativo de espécie rara (Grupo 1), bem como a fuga do padrão temporal de frequência ou dominância do recife pelas espécies do Grupo 2, são indícios da ocorrência de impactos. Este trabalho fornece à gestão do Recife de Formosa uma eficiente ferramenta para avaliação do impacto urbano sobre a comunidade macrofitobêntica.

Palavras-chave: Macroalgas; Biomonitoramento; Seleção de espécies bioindicadoras; Qualidade ambiental; Gestão Ambiental.

Abstract. Evaluation and proposal for monitoring the state of conservation of the coastal reef environment of the State of Paraíba, Brazil: contributions to environmental management. Urbanization in Coastal areas makes it necessary to assess the anthropic impact on associated ecosystems. The objective of this study was to analyze temporally the dynamics of macroalgae populations with bioindicator potential, establishing them as a tool for environmental health assessment. Formosa's intertidal coral reef environment (Paraíba/Brazil) was sampled with quarterly intervals from August, 2013 to November, 2014. The temporal variation of the frequency of occurrence $\left(\mathrm{F}^{\prime}\right)$ of the macrophytobenthic populations was evaluated through the Analysis of Variance (One-Way Anova) with test Post-Hoc of Tukey The influence of environmental variables on $F^{\prime}$ was evaluated through the Linear Correlation of Pearson and PERMANOVA. The environmental quality analysis and the proposal of biomonitoring were based on Group 1, formed by perennial and/or rare species with higher values along Principal Component 1 (PC1) of Principal Component Analysis (PCA), and Group 2, formed by species with erratic behavior with lower values along the PC1 of the PCA. 33 macrophytobenthic species were evaluated. The frequency of occurrence showed temporal variation, but was not influenced by the set of environmental variables. Phyllodictyon anastomosans, Gelidiella acerosa and Gelidium corneum composed Group 1, with Dictyopteris delicatula, Canistrocarpus cervicornis and Hypnea spinella forming Group 2. Group 2 presented a positive correlation with temperature, reaching maximum frequencies in the hotter periods, but this factor alone cannot explain the erratic distribution of species. The occurrence of eutrophication bioindicators was considered natural, a fact that coupled with the high frequency of bioindicator species of environmental quality, suggests that the Formosa's reef does not suffer significant anthropic impacts. The disappearance of perennial species or significant population growth of rare species (Group 1), as well the standard temporal fugue frequency or growth dominance by Group 2 species, are indications of the occurrence of impacts. The Formosa's Reef management was provided with an efficient tool for assessing the impact on the macrophytobenthic community.

Keywords: Macroalgae; Biomonitoring; Selection of bioindicator species; Environmental Quality; Environmental Management. 


\section{Introdução}

Com destacada importância ecológica e econômica (Moberg e Folke, 1999), os ambientes recifais estão sob ameaça do crescente impacto antrópico (Estes et al., 2011), sendo especialmente fortes nas zonas costeiras (Galvão e Nolasco, 2013). A urbanização é um dos modos mais intensos de transformação dos ambientes naturais (McKinney, 2002), tendo o turismo (Oigman-Pszczol e Creed, 2011; Sarmento e Santos, 2012) e, principalmente, a poluição, como tensores que, isolados ou combinados, produzem mudanças na saúde ambiental dos ambientes recifais, afetando a estrutura (Scherner et al., 2012), o funcionamento, a biodiversidade e a resiliência da comunidade recifal (Melo et al., 2008).

Ocorrendo ao longo de grande parte da costa (Costa et al., 2007), a beleza natural dos recifes do Estado da Paraíba representa um importante atrativo turístico. No entanto, impactos decorrentes dessa atividade, como pisoteio, movimentação e ancoragem de embarcações, lixo, dentre outros (Lourenço, 2010), aliados aos efeitos sinérgicos da industrialização, desmatamento (Silva, 2013), pesca artesanal, coletas de algas (Souza et al., 2007) e poluição, vêm tornando emergencial o diagnóstico da saúde desses ecossistemas e a tomada de ações conservacionistas (Costa, 2016).

Estudos que objetivem a avaliação da saúde ambiental, identificando o impacto da urbanização sobre os ecossistemas são essenciais para o aumento ou manutenção da qualidade ambiental. Em um país que visa a atingir as metas de Aichi até 2020, preservando sua vasta biodiversidade e utilizando as unidades de conservação (UCs) como uma das ferramentas, estudos de análise da qualidade ambiental são importantes para avaliação da efetividade do manejo (nas UCs já implementadas) e planejamento para criação de novas UCs (Mikkelsen e Cracraft, 2001).

$$
\text { Como etapa posterior à }
$$

identificação da saúde ecossistêmica, muitos estudos voltados para a Biologia da Conservação elaboram ou aplicam propostas de monitoramento ambiental diante do suporte que esta etapa traz em processos de tomada de decisão, políticas públicas e ações de manejo com base nas tendências observadas nas populações e comunidades biológicas (Silva, 2013). Essenciais em planejamento e gestão ambiental, especialmente em áreas protegidas (Francini-Filho e Moura, 2008), os monitoramentos ambientais permitem avaliar o impacto de ações conservacionistas, bem como as respostas da comunidade a impactos externos (estocásticos ou não e de origem natural ou antrópica) (Mikkelsen e Cracraft, 2001).

Uma das principais ferramentas utilizadas em programas de avaliação e monitoramento ambiental é a bioindicação (Areces Mallea, 2015), podendo-se estabelecer desde populações até ecossistemas como indicadores biológicos. Em ecossistemas aquáticos, o papel das macroalgas como bioindicadores é bem reconhecido, devido a características intrínsecas como: são organismos sésseis, possuem biomassa suficiente para detecção de alterações, têm ampla distribuição, são facilmente coletáveis, acumulam metais, dentre outros aspectos ecológicos, fisiológicos e morfológicos (Pinedo et al., 2007). Distúrbios em ecossistemas recifais são percebidos através de fenômenos simultâneos e inversos na comunidade algal: (I) fixação e desenvolvimento de espécies seletivas/oportunistas; (II) diminuição significativa de espécies sensíveis, isto é, aquelas suscetíveis a impactos antrópicos (Littler et al., 2006). Porém, um questionamento é frequente ao utilizar o método da bioindicação para avaliações e 
monitoramento de ambientes recifais: "qual quantidade algal é natural em um recife e quanto é demais - ou muito pouco?" São necessários estudos temporais bem delineados a fim de conhecer o padrão da comunidade macrofitobêntica local, evitando conclusões sobre o tempo presente e propostas de monitoramento falhas (Bruno et al., 2014).

Políticas e gestões ambientais com foco na conservação da biodiversidade costeira e marinha são essenciais para a manutenção de populações viáveis de espécies nativas em habitats naturais e, consequentemente, da qualidade ecossistêmica (Floriano, 2007). O gerenciamento correto dos ecossistemas requer o conhecimento sobre o estado pristino local, ou seja, como era sua composição e dinâmica antes que os humanos começassem a esgotá-los, alterá-los e degradá-los. Porém, os gestores raramente têm informações confiáveis sobre os estados pristinos pelo simples fato de não haver coleta de dados em tempos em que o impacto antrópico não era significativo ou não preocupava (Dayton et al., 1998). Em ecossistemas costeiros e marinhos há elevadas dificuldades e custos nas avaliações e monitoramento da qualidade ambiental (Bruno et al., 2014).

Na Paraíba, é de responsabilidade da Superintendência de Administração do Meio Ambiente (SUDEMA) questões ligadas à gestão ambiental, como o desenvolvimento de ações de licenciamento, cadastramento, educação e fiscalização ambiental, além de aspectos ligados à recuperação e monitoramento ambiental (SUDEMA, 2017). Os recifes costeiros paraibanos estão submetidos a modelos de gestão heterogêneos, o que gera diferentes tipos de proteção (Cabedelo, 2004; João Pessoa, 2004; Conde, 2008; Mataraca, 2010; Pitimbu, 2015) e usos (Costa et al., 2007). Mesmo as formações recifais estendendo-se ao longo de grande parte da costa, no estado há apenas duas unidades de conservação que possuem recifes sobre proteção: o Parque Estadual Marinho de Areia Vermelha e a APA da Barra do Rio Mamanguape (MMA, 2017).

A identificação de áreas com boa qualidade ambiental e elaboração de propostas de monitoramento podem servir de base de dados ou incorporadas a planos de gestão. Nesse contexto, este trabalho objetivou analisar sob a escala temporal a dinâmica de populações de macroalgas com potencial bioindicador no ambiente recifal de Formosa, estabelecendo-a como ferramenta para avaliação e monitoramento do estado de conservação local.

\section{Material e Métodos}

\section{Área de Estudo}

0 estudo foi desenvolvido sobre o recife da região mesolitorânea da Praia de Formosa, Estado da Paraíba, Nordeste do Brasil (6 $6^{\circ} 59^{\prime} 04^{\prime \prime} \mathrm{S}$; 34 $34^{\circ}$ ' 56" W, Figura 1), distante cerca de $1,5 \mathrm{~km}$ da costa e aflorando sob marés abaixo de 0,4 m. Compondo a Região Ficogeográfica Tropical (Horta et al., 2001) e distante cerca de $2 \mathrm{~km}$ do ambiente recifal de Areia Vermelha, forte ponto turístico do estado, que recebe milhares de visitantes ao ano (Lourenço, 2015), o Recife de Formosa possui substrato consolidado formado principalmente por algas calcárias e elementos coralíneos de origem animal sob sedimento arenoso, recebendo atividade turística eventual.

De acordo com a classificação climática proposta por Köppen (1900), o clima da região é As', caracterizando-se por ser quente e úmido (Governo do Estado da Paraíba, 1985), com temperatura variando entre $22^{\circ} \mathrm{C}$ e $26^{\circ} \mathrm{C}$. A estação chuvosa inicia-se em março e estende-se até agosto. A estação seca começa em setembro e prolonga-se até fevereiro (Feliciano e Melo, 2003). 


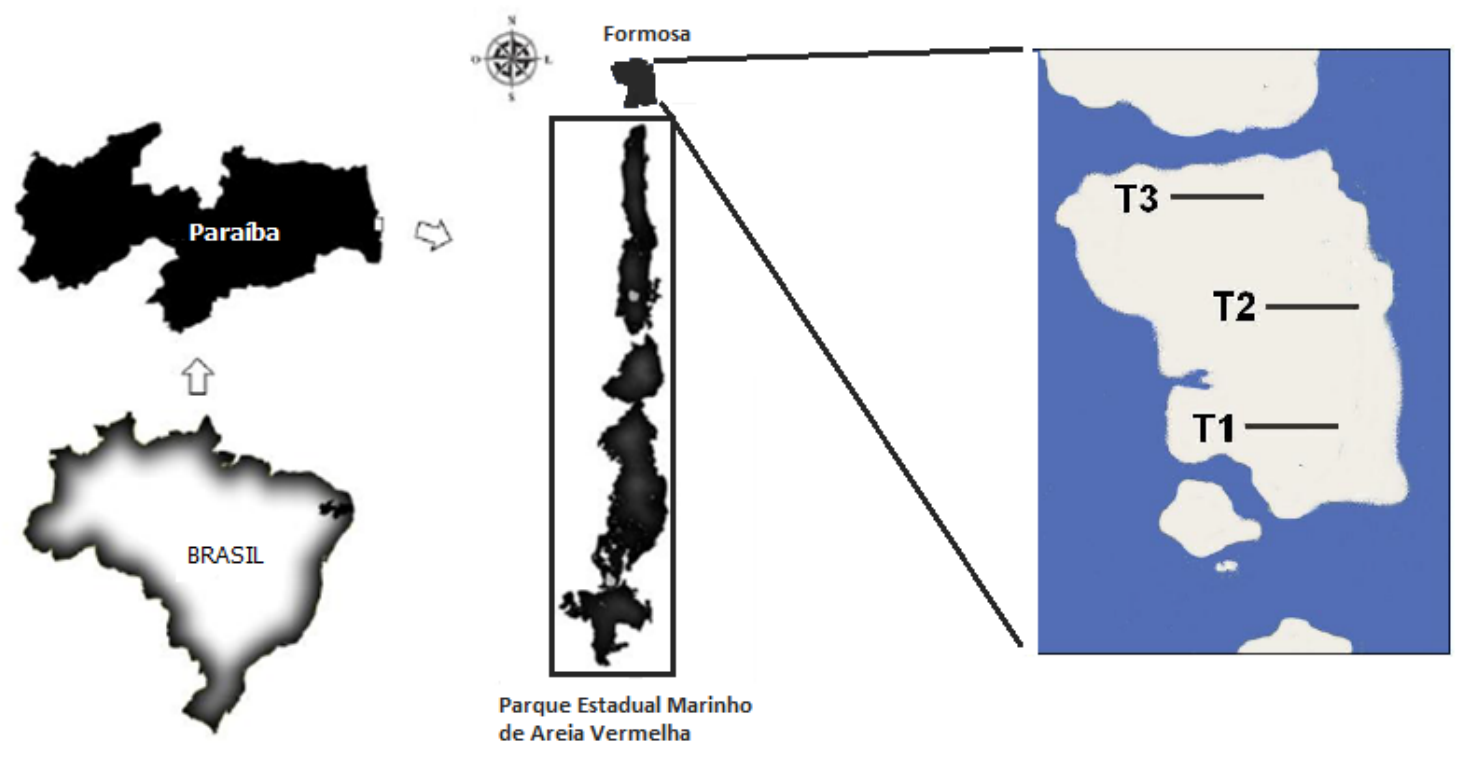

Figura 1. Detalhamento da área de estudo. T1 - Transecto 1; T2 - Transecto 2; T3 - Transecto 3. Adaptado de Costa (2016) e Máximo (2015).

\section{Estação de coletas e delineamento amostral \\ Foram \\ lançados} perpendicularmente à linha da costa três transectos com $20 \mathrm{~m}$ de comprimento, marcados a cada $0,5 \mathrm{~m}$ e distando do mais próximo cerca de $100 \mathrm{~m}$ (Figura 1).

Foram realizadas seis coletas com intervalos trimestrais ao longo de 15 meses: agosto/2013, novembro/2013, fevereiro/2014, maio/2014, agosto/ 2014 e novembro/2014. Em cada transecto foram sorteados 10 pontos e plotadas unidades amostrais de $20 \times 20 \mathrm{~cm}\left(0,04 \mathrm{~m}^{2}\right)$, em que todas as macroalgas encontradas no interior das mesmas foram coletadas, armazenadas em sacos plásticos e congeladas para posterior triagem no Laboratório de Algas Marinhas da UFPB. Após triagem e identificação, a classificação taxonômica da espécies foi atualizada de acordo com Guiry e Guiry (2018).

\section{Caracterização ambiental}

Médias trimestrais anteriores a cada período (incluindo-o) das variáveis ambientais foram obtidas no site Ocean
Color (2016) e no Instituto Nacional de Meterologia (INMET). Foram elas: precipitação, subsidência da radiação fotossintética no ar (PAR), subsidência da radiação fotossintética na água do mar (IPAR), temperatura da superfície do mar, concentração da massa de clorofila, concentração de carbono orgânico na água do mar, temperatura atmosférica.

\section{Seleção das espécies bioindicadoras e análises estatísticas}

Análises de variância (one-way ANOVA with repeated measures) foram realizadas para avaliarem a variação temporal entre os períodos amostrais das variáveis ambientais e da frequência (F') das espécies, calculada a partir da média percentual de ocorrência (presença/ausência) nas unidades amostrais em cada transecto. Teste $a$ posteriori de Tukey pareado analisou possíveis diferenças entre os períodos amostrais. A priori, os dados foram submetidos a Teste de Normalidade Shapiro-Wilk e Teste de Homocedasticidade de Levene. 
De acordo com a frequência de ocorrência ao longo dos períodos amostrais, as espécies foram classificadas em: (I) perenes, que ocorreram com $\mathrm{F}^{\prime}>10 \%$ e com médias mensais semelhantes; (II) erráticas, apresentaram marcada diferença entre as médias mensais de F'; (III) Raras, ocorrendo com $\mathrm{F}^{\prime}=10 \%$ em único período amostral; (IV) Raríssimas, não alcançando $\mathrm{F}^{\prime}>10 \%$ em nenhum período.

Para a seleção das espécies bioindicadoras foi realizada a análise de componentes principais (ACP) com base nas médias mensais de $\mathrm{F}^{\prime}$ das espécies. Foram selecionadas as espécies com os maiores e menores valores ao longo do Componente Principal 1 da ACP, objetivando assim identificar as espécies que mais e que menos explicaram o padrão temporal de $\mathrm{F}^{\prime}$ demonstrado pela ACP. Nesta etapa as espécies classificadas como Raríssimas foram excluídas pelo nível extremo de raridade local. Propõese um método de seleção e monitoramento com base em dois grupos de espécies bioindicadoras: Grupo 1, formado por espécies perenes e/ou raras que apresentaram os menores valores ao longo do Componente Principal 1; e Grupo 2, formado por espécies erráticas que apresentaram os maiores valores ao longo do Componente Principal 1. Além disso, promoveu-se uma revisão na literatura acerca do potencial bioindicador das espécies selecionadas.

A avaliação da influência das variáveis ambientais sobre a flutuação temporal de $F^{\prime}$ das populações bioindicadoras selecionadas foi feita para-par pela tabela de Correlação com coeficiente linear de Pearson (r) e de forma agrupada pela Análise de variância multivariada permutacional (PERMANOVA, 9.999x) com Índice de Distância Bray-Curtis.

Todos os testes e análises foram realizados com o auxílio do software Past 3.14 .

\section{Resultados}

\section{Variação temporal de $F^{\prime}$ e espécies bioindicadoras}

Foi encontrado um total de 33 espécies de macroalgas, 8 Chlorophyta, 6 Ochrophyta (Phaeophyceae) e, 19 Rhodophyta (Tabela 1). Destas, 10 foram consideradas Perenes, 8 Erráticas, 3 Raras e 12 Raríssimas.

Tabela 1. Médias das frequências de ocorrência $\left(F^{\prime}\right)$ nos períodos amostrais.

\begin{tabular}{lcccccc}
\hline Espécies & Ago/13 & Nov/13 & Fev/14 & Mai/14 & Ago/14 & Nov/14 \\
\hline Bryopsis pennata & 3,33 & 16,67 & 26,67 & 0,00 & 6,67 & 6,70 \\
Bryopsis plumosa & 0,00 & 0,00 & 0,00 & 3,33 & 0,00 & 0,00 \\
Caulerpa racemosa & 14,17 & 20,00 & 16,67 & 13,33 & 20,00 & 10,00 \\
Caulerpa sertularioides & 3,33 & 0,00 & 0,00 & 0,00 & 0,00 & 0,00 \\
Ernodesmis verticillata & 10,00 & 0,00 & 3,33 & 0,00 & 0,00 & 0,00 \\
Penicillus capitatus & 4,17 & 0,00 & 0,00 & 0,00 & 0,00 & 0,00 \\
Phyllodictyon anastomosans & 0,00 & 3,33 & 0,00 & 0,00 & 0,00 & 10,00 \\
Dictyota mertensii & 13,33 & 6,67 & 23,33 & 0,00 & 0,00 & 0,00 \\
Canistrocarpus cervicornis & 0,00 & 26,67 & 30,00 & 60,00 & 0,00 & 3,30 \\
Dictyopteris delicatula & 10,83 & 23,33 & 70,00 & 90,00 & 3,33 & 13,70 \\
Lobophora variegata & 0,00 & 0,00 & 0,00 & 3,33 & 0,00 & 0,00 \\
Dictyopteris justii & 0,00 & 0,00 & 6,67 & 0,00 & 0,00 & 0,00 \\
Sargassum vulgare & 0,00 & 0,00 & 3,33 & 0,00 & 0,00 & 0,00 \\
Acantophora spicifera & 31,67 & 23,33 & 46,67 & 53,33 & 13,33 & 20,37 \\
Aglaothamnion uruguayense & 6,67 & 6,67 & 3,33 & 10,00 & 0,00 & 0,00 \\
Bryothamnion seaforthii & 0,00 & 0,00 & 0,00 & 0,00 & 3,33 & 0,00 \\
Centroceras clavulatum & 0,00 & 3,33 & 0,00 & 0,00 & 6,67 & 0,00
\end{tabular}


Tabela 1. Continuação.

\begin{tabular}{lcccccc}
\hline Espécies & Ago/13 & Nov/13 & Fev/14 & Mai/14 & Ago/14 & Nov/14 \\
\hline Chondracanthus acicularis & 73,33 & 80,00 & 73,33 & 56,67 & 66,67 & 79,26 \\
Cryptonemia crenulata & 0,00 & 3,33 & 3,33 & 3,33 & 6,67 & 0,00 \\
Gelidium crinale & 72,50 & 66,67 & 93,33 & 90,00 & 80,00 & 93,33 \\
Gelidium corneum & 30,83 & 13,33 & 23,33 & 36,67 & 30,00 & 27,78 \\
Gelidium pusillum & 0,00 & 0,00 & 0,00 & 0,00 & 10,00 & 31,85 \\
Gelidiella acerosa & 96,67 & 96,67 & 96,67 & 100,00 & 90,00 & 100,00 \\
Gracilaria cervicornis & 0,00 & 6,67 & 26,67 & 13,33 & 10,00 & 0,00 \\
Gracilaria sp. & 35,83 & 16,67 & 26,67 & 10,00 & 10,00 & 30,74 \\
Hypnea musciformis & 0,00 & 20,00 & 13,33 & 3,33 & 0,00 & 27,41 \\
Hypnea spinella & 6,67 & 30,00 & 46,67 & 50,00 & 6,67 & 20,00 \\
Laurencia clavata & 26,67 & 73,33 & 70,00 & 56,67 & 53,33 & 81,85 \\
Haloplthys schottii & 0,00 & 3,33 & 0,00 & 0,00 & 0,00 & 0,00 \\
Solieria sp & 0,00 & 0,00 & 3,33 & 0,00 & 3,33 & 0,00 \\
Vidalia sp & 0,00 & 0,00 & 0,00 & 3,33 & 0,00 & 0,00 \\
Halimeda opuntia & 30,00 & 56,67 & 46,67 & 73,33 & 60,00 & 48,15 \\
Amphiroa fragilissima & 72,50 & 90,00 & 100,00 & 100,00 & 76,67 & 92,96 \\
\hline
\end{tabular}

Ago $/ 13=$ agosto $/ 2013 ; \quad$ Nov $/ 13=$ novembro $/ 2013 ; \quad$ Fev $/ 14=$ fevereiro $/ 2014 ; \quad$ Mai $/ 14=$ maio/2014; Ago/14 = agosto/2014; Nov/14 = novembro/2014 .

Diante da normalidade e homocedasticidade dos dados, a Frequência das espécies apresentou variação temporal significativa (ANOVA: $\mathrm{F}=4,288 ; \mathrm{p}=0,001)$. 0 Teste de Tukey pareado indicou haver diferenças entre os meses agosto/2013 e agosto/2014 em relação aos períodos de fevereiro/2014 e maio/2014 (Tabela 2). A análise de componentes principais (Figura 2) mostrou um Componente Principal 1 explicando 63,13\% da variação obtida e opondo o grupo formado por agosto/2013 e agosto/2014 ao grupo formado por fevereiro/2014 e maio/2014. Os períodos de novembro/2013 e novembro/2014 parecem representar um período de transição na F' das espécies.

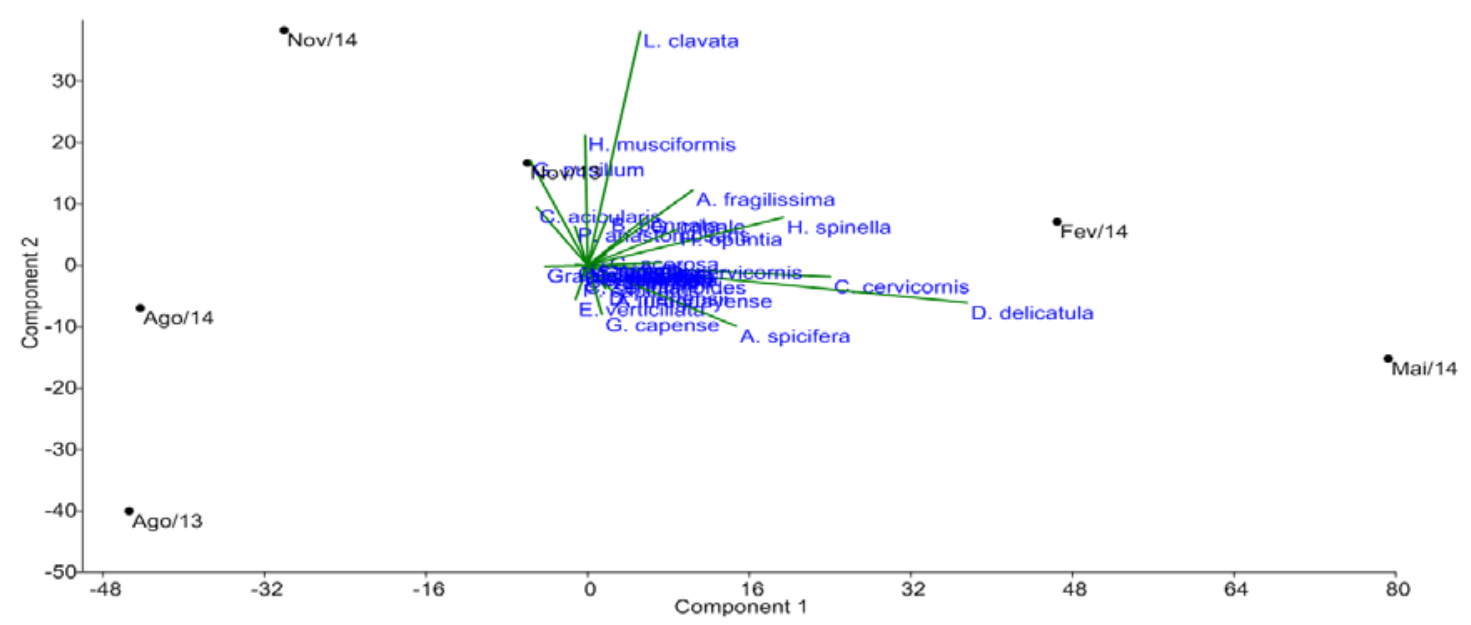

Figura 2. Diagrama de ordenação resultado da análise de componentes principais (ACP), representando a distribuição dos períodos amostrais e a relação com as frequências de ocorrência $\left(F^{\prime}\right)$ das espécies. Ago/13 = agosto/2013; Nov/13 = novembro/2013; Fev/14 = fevereiro/2014; Mai $/ 14$ = maio $/ 2014 ;$ Ago/14 = agosto/2014; Nov/14 = novembro/2014. 
Tabela 2. Comparação entre os períodos amostrais das frequências de ocorrência ( $\left.F^{\prime}\right)$ das espécies (Teste de Tukey pareado $-\mathrm{Q} \backslash \mathrm{p}$; $^{*}=\mathrm{p}<0,05$ ).

\begin{tabular}{|c|c|c|c|c|c|c|}
\hline & .Ago/13 & .Nov/13 & .Fev/14 & .Mai/14 & Ago/14 & .Nov/14 \\
\hline Ago/13 & & 0,591 & $0,006^{*}$ & $0,0168^{*}$ & 1 & 0,658 \\
\hline .Nov/13 & 2,278 & & 0,426 & 0,598 & 0,694 & 1 \\
\hline$. \mathrm{Fev} / 14$ & 4,911 & 2,633 & & 0,999 & $0,011^{*}$ & 0,363 \\
\hline .Mai/14 & 4,541 & 2,263 & 0,37 & & $0,027^{*}$ & 0,53 \\
\hline .Ago/14 & 0,223 & 2,055 & 4,687 & 4,317 & & 0,756 \\
\hline .Nov/14 & 2,134 & 0,144 & 2,778 & 2,407 & 1,91 & \\
\hline
\end{tabular}

Ago/13 = agosto/2013; $\quad$ Nov/13 = novembro/2013; $\quad$ Fev/14 = fevereiro/2014; $\quad$ Mai $/ 14=$ maio/2014; Ago/14 = agosto/2014; Nov/14 = novembro/2014.

Considerando como critérios para seleção das espécies bioindicadoras os valores de distribuição das espécies ao longo do Componente Principal 1 da ACP (Tabela 3) e a classificação das espécies de acordo com a frequência (Tabela 1), o
Grupo 1 foi formado pelas espécies Phyllodictyon anastomosans, Gelidiella acerosa e Gelidium corneum, enquanto o Grupo 2 por Dictyopteris delicatula, Canistrocarpus cervicornis e Hypnea spinella.

Tabela 3. Valores de distribuição das espécies ao longo do Componente Principal 1 da ACP.

\begin{tabular}{lc}
\hline Espécies & Componente Principal 1 \\
\hline Bryopsis pennata & 0,03662 \\
Caulerpa racemosa & $-0,04837$ \\
Ernodesmis verticillata & $-0,0594$ \\
Phyllodictyon anastomosans* & $-0,02399$ \\
Dictyota mertensii & 0,05665 \\
Canistrocarpus cervicornis** & 0,4404 \\
Dictyopteris delicatula** & 0,687 \\
Acantophora spicifera & 0,2701 \\
Aglaothamnion uruguayense & 0,04525 \\
Chondracanthus acicularis & $-0,09302$ \\
Gelidium crinale & 0,1068 \\
Gelidium corneum* & 0,02592 \\
Gelidium pusillum & $-0,1048$ \\
Gelidiella acerosa* & 0,03428 \\
Gracilaria cervicornis & 0,1354 \\
Gracilaria sp. & $-0,07959$ \\
Hypnea musciformis & $-0,0447$ \\
Hypnea spinella** & 0,3551 \\
Laurencia clavata & 0,095 \\
Halimeda opuntia & 0,1628 \\
Amphiroa fragilissima & 0,1907 \\
\hline
\end{tabular}

* = espécie bioindicadora do Grupo 1; ** = espécie bioindicadora do Grupo 2. 


\section{Influência das variáveis ambientais sobre variação temporal de $F^{\prime}$}

Apesar da região possuir um reconhecido padrão sazonal no qual um conjunto de condições ambientais se alteram entre as estações seca e chuvosa (Rao et al., 1993), não foram detectadas variações temporais nas condições ambientais locais (ANOVA: $\mathrm{F}=1,991$; $p=0,108)$. Em resposta à manutenção do padrão ambiental ao longo dos períodos (Figura 3), o conjunto de variáveis ambientais não influenciaram as variações temporais de frequência das populações bioindicadoras (PERMANOVA: $\mathrm{F}=1 ; \mathrm{p}=0,39$ ), porém a análise isolada de cada variável sobre as populações indicou uma correlação positiva entre as temperaturas (atmosférica e marinha) e a $F^{\prime}$ das espécies do Figura 4 (Tabela 4).
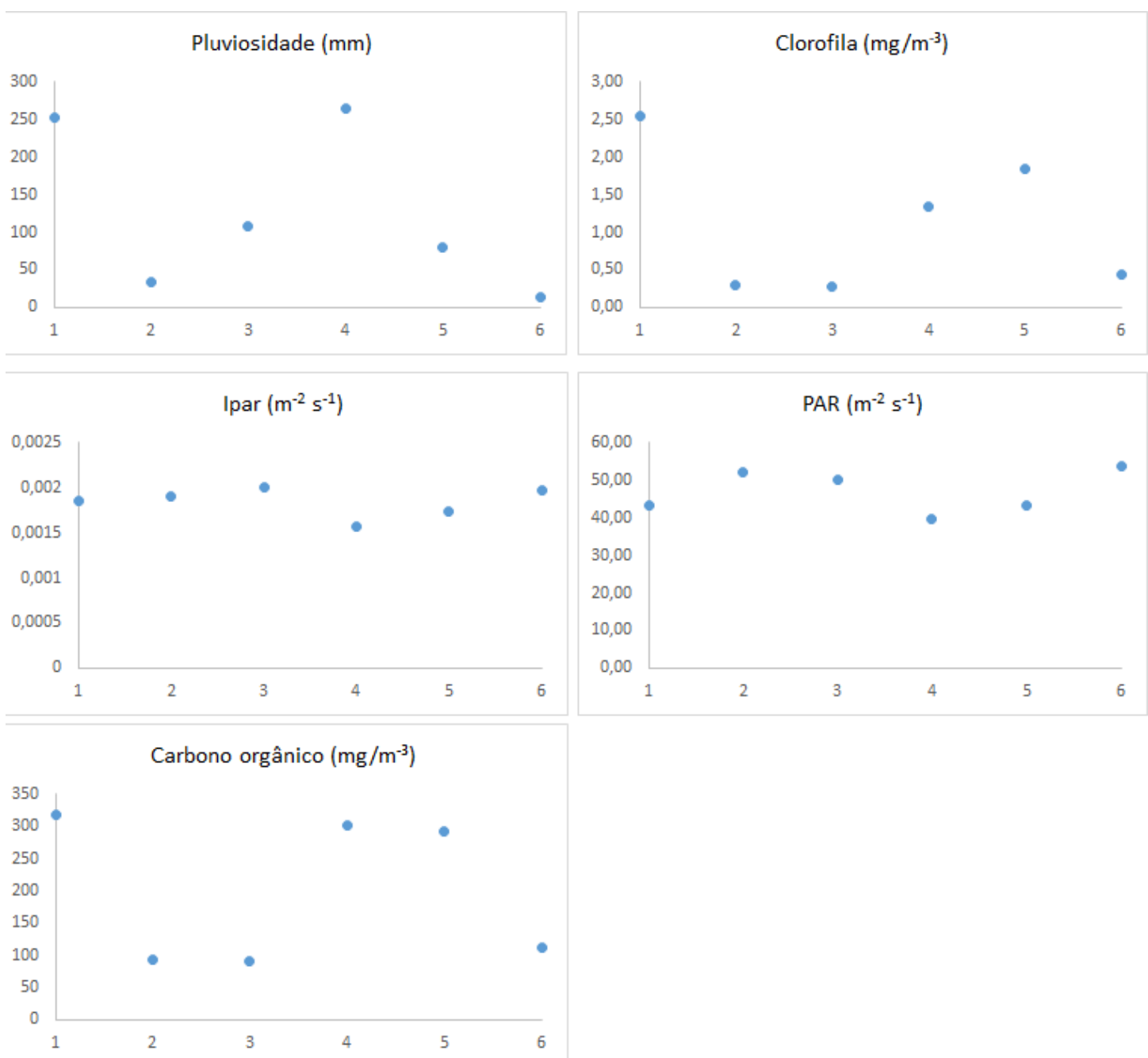

Figura 3. Variação temporal das variáveis ambientais no ambiente recifal de Formosa/PB. Variações de temperatura (marinha e atmosférica) detalhadas na Figura 4. 1=agosto/2013; $2=$ novembro $/ 2014 ; 3$ = fevereiro $/ 2014 ; 4=$ maio $/ 2014 ; 5=$ agosto $/ 2014 ; 6=$ novembro $/ 2014$. 


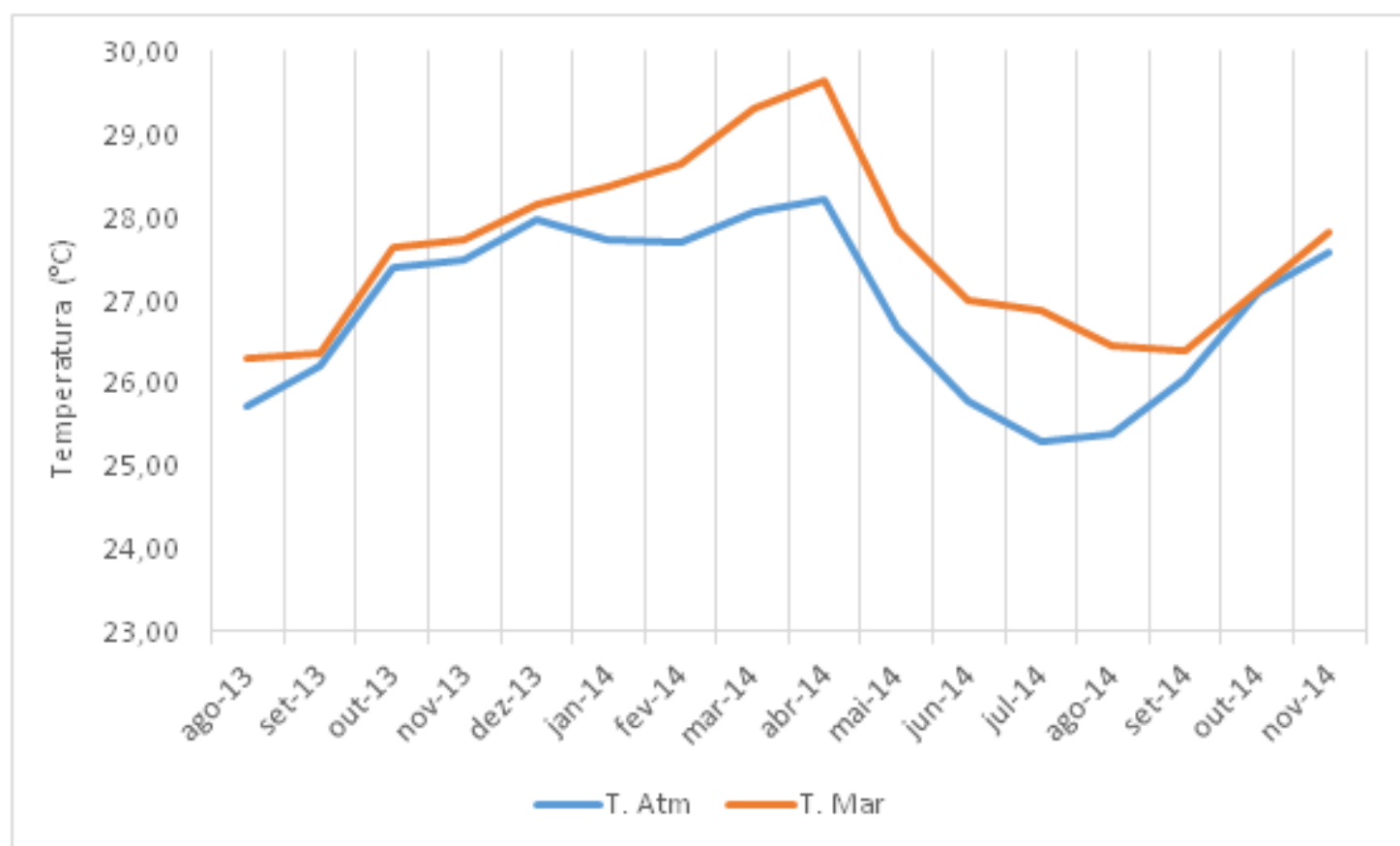

Figura 4. Variação temporal das temperaturas marinha e atmosférica ao longo do período de estudo. T. Mar = Temperatura da superfície do mar; T. Atm = Temperatura do ar.

Tabela 4. Tabela de correlação (coeficiente linear de Pearson-r/p) entre os parâmetros ambientais e as espécies bioindicadoras selecionadas.

\begin{tabular}{|c|c|c|c|c|c|c|c|}
\hline & & C. cerv. & D. deli. & H. spin. & G. coar. & G. acer. & P. anas. \\
\hline \multirow{2}{*}{ TempMar } & $r$ & 0,916 & 0,994 & 0,911 & 0,232 & 0,569 & $-0,304$ \\
\hline & $\mathrm{p}$ & $0,01^{*}$ & $0,004^{*}$ & $0,011^{*}$ & 0,658 & 0,238 & 0,557 \\
\hline \multirow{2}{*}{ TempAtm } & $r$ & 0,797 & 0,825 & 0,800 & $-0,179$ & 0,648 & 0,125 \\
\hline & $\mathrm{p}$ & $0,047^{*}$ & $0,042^{*}$ & $0,045^{*}$ & 0,733 & 0,163 & 0,813 \\
\hline \multirow{2}{*}{ Precip. } & $r$ & $-0,271$ & $-0,260$ & $-0,304$ & 0,403 & $-0,085$ & $-0,419$ \\
\hline & $\mathrm{p}$ & 0,603 & 0,618 & 0,557 & 0,428 & 0,872 & 0,408 \\
\hline \multirow{2}{*}{ Clorof. } & $r$ & $-0,663$ & $-0,60$ & $-0,616$ & 0,376 & $-0,640$ & $-0,388$ \\
\hline & $\mathrm{p}$ & 0,150 & 0,205 & 0,192 & 0,461 & 0,170 & 0,446 \\
\hline \multirow{2}{*}{ Par } & $r$ & 0,373 & 0,321 & 0,394 & $-0,623$ & 0,495 & 0,536 \\
\hline & $\mathrm{p}$ & 0,465 & 0,534 & 0,439 & 0,186 & 0,318 & 0,273 \\
\hline \multirow{2}{*}{ Carbono } & $\mathrm{r}$ & $-0,437$ & $-0,386$ & $-0,453$ & 0,572 & $-0,469$ & $-0,489$ \\
\hline & $\mathrm{p}$ & 0,386 & 0,449 & 0,367 & 0,235 & 0,348 & 0,324 \\
\hline \multirow{2}{*}{ IPAR } & $r$ & 0,226 & 0,276 & 0,343 & $-0,647$ & 0,533 & 0,455 \\
\hline & $\mathrm{p}$ & 0,386 & 0,449 & 0,367 & 0,235 & 0,348 & 0,324 \\
\hline
\end{tabular}

TempMar = temperatura da superfície do mar; TempAtm = temperatura atmosférica; Precip. = Precipitação; Clorof. = concentração da massa de clorofila; Par = subsidência da radiação fotossintética no ar; Carbono = concentração de carbono orgânico na água do mar; IPAR = subsidência da radiação fotossintética na água do mar. C. cerv. = Canistrocarpus cervicornis; $D$. deli. = Dictyopteris delicatula; H. spin. = Hypnea spinella; G. coar. = Gelidium coarctatum; G. acer. = Gelidiella acerosa; $P$. anas. $=$ Phyllodictyon anastomosans. 


\section{Estado de conservação local e biomonitoramento}

Baseado no comportamento perene e com altas taxas de frequência de espécies bioindicadoras de qualidade ambiental, bem como o comportamento errático (entendido como natural) de espécies bioindicadoras de eutrofização, sugere-se que o ambiental recifal da Praia de Formosa-PB não deve sofrer impactos antrópicos significativos.

A seleção de grupos de espécies com comportamento temporal e potencial bioindicador opostos é uma ferramenta em programas de monitoramento do recife, tendo como base a avaliação da manutenção do padrão temporal de frequência encontrado (Figuras 5 e 6). Desaparecimento de espécies perenes bioindicadoras de qualidade ambiental ou crescimento populacional significativo, independente do período, de espécie rara (Grupo 1), bem como fuga do padrão temporal de frequência ou dominância do recife pelas espécies erráticas bioindicadoras de eutrofização (Grupo 2), são indícios da ocorrência de impactos.

\section{Discussão}

\section{Variação temporal de F'}

Analisando a variação temporal de frequência das espécies do Grupo 1 (Figura 5), nota-se que Phyllodictyon anastomosans atingiu $\mathrm{F}^{\prime}=10 \%$ em Novembro/14, enquanto Gelidiella acerosa e Gelidium corneum possuíram $\mathrm{F}^{\prime} \geq 10 \%$ em todos os períodos e médias mensais de frequência semelhantes. Além da perenidade ou raridade local, as espécies desse grupo se caracterizam por serem comuns em recifes mesolitorâneos submetidos a baixa influência de eutrofização. $P$. anastomosans não é capaz de se desenvolver em ambientes que estejam sobre forte influência do descargo de dejetos (Dhargalkar e Komarpant, 2003). Freire et al. (2007) e Gorostiaga e Díez (1996) avaliaram os potenciais de crescimentos de G. acerosa e G. corneum, respectivamente, e verificaram baixo potencial de desenvolvimento das espécies em águas eutrofizadas. Condições ambientais adversas como baixa salinidade e elevada turbidez também são limitantes para $G$. acerosa (Freire et al., 2007), sendo a espécie mais frequente no presente estudo, estando presente em média $96,6 \%$ das unidades amostrais.

Em Ecologia, o conceito de espécie rara apresenta gradientes que variam entre extremos de raridade e casos mais brandos (Rabinowitz et al., 1986). A definição de um limiar quantitativo na classificação como rara de uma espécie em determinado ambiente é controversa, porém Gaston (1994) propôs algo próximo do consensual ao classificar como raras aquelas espécies que apresentam abundância individual menor do que $20 \%$. Sob riscos de extinção local, perda de variabilidade genética e com a mesma importância das raras, as espécies perenes também devem ser consideradas para estudos de indicação de impactos (Scarano, 2006). 


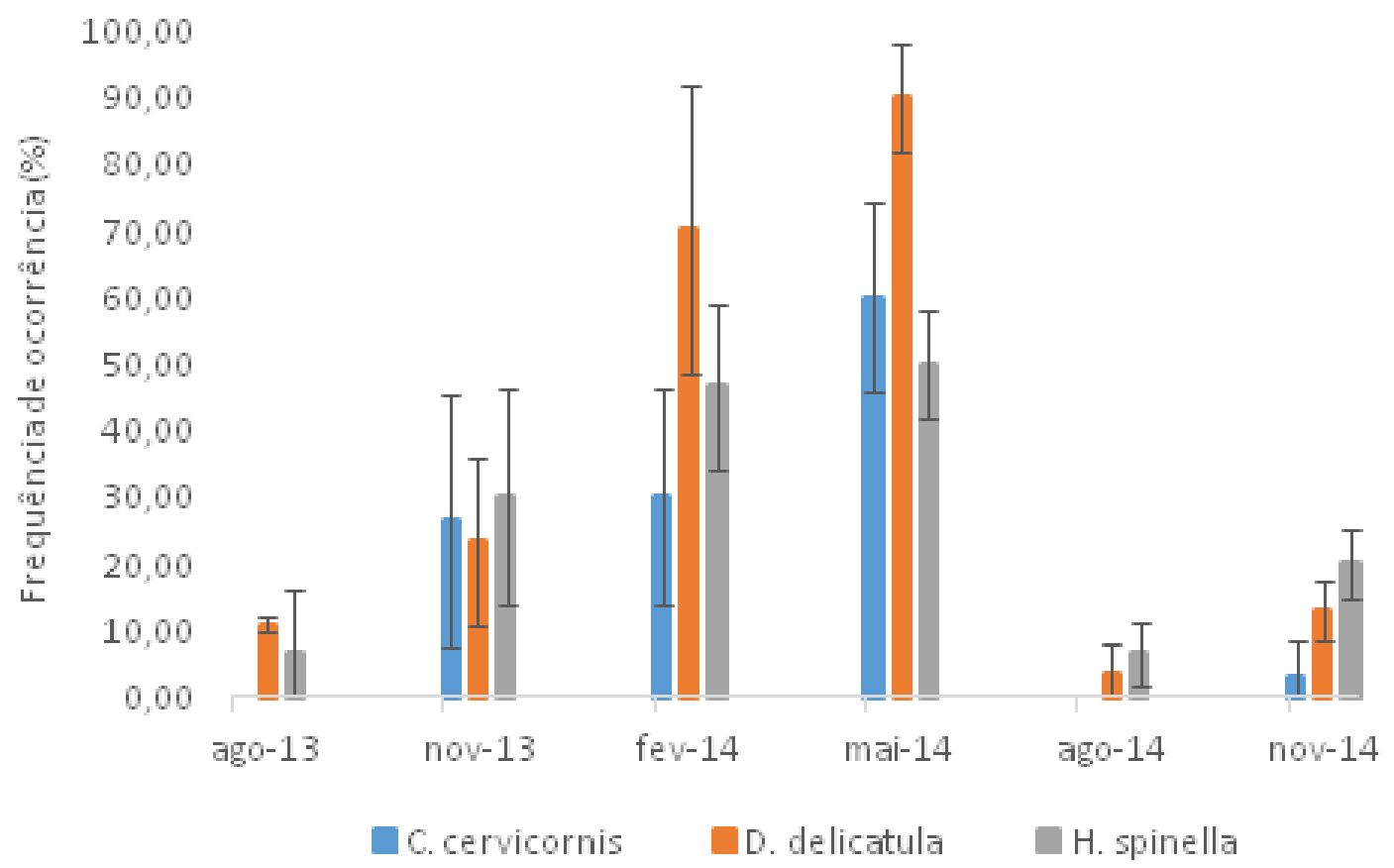

Figura 5. Padrão temporal de frequência das espécies bioindicadoras do Grupo 2. ago/13 = agosto/2013; nov/13 = novembro/2013; fev/14 = fevereiro/2014; mai $/ 14$ = maio/2014; ago/14 = agosto/2014; nov/14 = novembro/2014.

No Grupo 2, Dictyopteris delicatula, Canistrocarpus cervicornis e Hypnea spinella apresentaram diferença entre as elevadas médias alcançadas em fevereiro/2014 e maio/2014 em comparação com as baixas médias nos demais períodos (Figura 6). Além do comportamento errático local das espécies, os gêneros desse grupo foram classificados por Orfanidis et al. (2003) como oportunistas, por possuírem altas taxas de crescimento e ciclos de vidas curtos. D. delicatula é encontrada em ambientes recifais que possuem atividade turística, sendo tolerante ao pisoteio e outros distúrbios de origem turística (Azevedo et al., 2011). H. spinella foi classificada por Moreira et al. (2006) como oportunista e típica de área perturbada. Silva et al. (2012) ao avaliarem a atividade turística em outro ambiente recifal do nordeste brasileiro, identificaram $H$. spinella como componente do grupo de algas corticadas características de áreas impactadas pelo turismo. Canistrocarpus cervicornis é uma espécie oportunista (Littler e Littler, 1980; Steneck e Dethier, 1994) com reconhecida capacidade de responder rapidamente ao enriquecimento de nutrientes do ambiente, aumentando a taxa de crescimento (Fong et al., 2003). Pereira et al. (2002) verificaram a elevada frequência de ocorrência de C. cervicornis em ambiente recifal próximo impactado pelo turismo. 


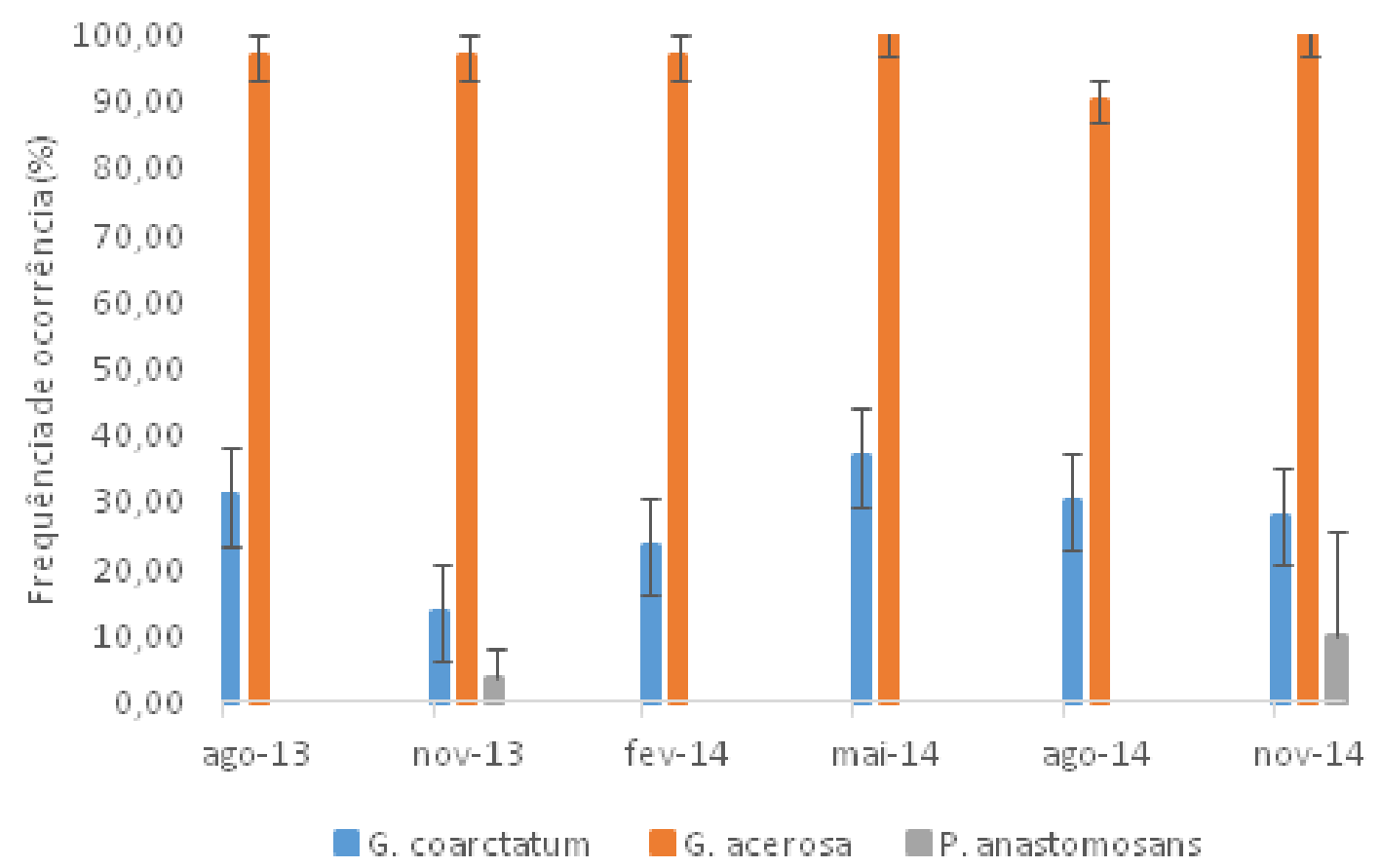

Figura 6. Padrão temporal de frequência das espécies bioindicadoras do Grupo 1. ago/13= agosto/2013; nov/13 = novembro/2013; fev/14 = fevereiro/2014; mai/14 = maio/2014; ago/14 = agosto $/ 2014 ;$ nov $/ 14$ = novembro $/ 2014$.

A ocorrência das espécies do Grupo 2 com potencial bioindicador de eutrofização é entendida como natural, pois como destacado por Areces Mallea et al. (2015), a ocorrência e abundância de espécies bioindicadoras de eutrofização com comportamento oportunista não necessariamente representam um sinal de alerta, pois em alguns ambientes ou períodos esse evento é natural, caracterizando um comportamento sazonal. Em programas de monitoramento, a seleção de espécies deve estar ligada ao respectivo potencial bioindicador reconhecido na literatura, além da necessária detenção do seu comportamento temporal (Steneck e Dethier, 1994; Littler et al., 2006).

\section{Influência das variáveis ambientais sobre variação temporal de F'}

No Grupo 1, a perenidade de $G$. acerosa e $G$. corneum pode ser explicada pela não variação temporal do conjunto de condições ambientais aliada à plasticidade ecológica e resiliência das espécies, estando a raridade de $P$. anastomosans ligada a características intrínsecas da espécie e/ou a ação de fatores naturais ou antrópicos não avaliados que se comportaram diferentes em novembro/2014. Fontana e Sevegnani (2012) destacam que as espécies perenes de um ambiente possuem fácil adaptação e ampla distribuição e abundância, sendo utilizadas em programas de monitoramento devido a elevada adaptabilidade local.

G. acerosa (Vasconcellos et al., 2013) e G. corneum (Guerra-García et al., 2011) são comuns em ambientes de mesolitoral, apresentando grandes densidades ao longo das estações seca e chuvosa na porção setentrional do Atlântico Sul, o que reflete a tolerância à exposição ao vento durante a maré vazante. Em contrapartida, a raridade de $F^{\prime}$ de P. anastomosans reflete a sua baixa 
adaptabilidade no ambiente o que pode estar ligado à sua biologia reprodutiva, duração do ciclo de vida e habilidades de dispersão e de competição, os quais interagem sinergicamente com variáveis abióticas na determinação da taxas de crescimento e dinâmica populacional (Kunin e Gaston, 1993).

Diferente da perenidade ou raridade das espécies do Grupo 1, as espécies do Grupo 2 apresentaram frequências diferentes entre os períodos amostrais, porém não acompanharam os padrões sazonais anuais. Os maiores valores de F' das populações desse grupo acompanharam os máximos de temperatura atmosférica e da superfície da água dentre os períodos amostrais. A temperatura média dos oceanos exerce influência sobre o crescimento das macroalgas (Davison e Pearson, 1996), porém outros fatores como salinidade, disponibilidade de substratos, nutrientes, condições de luz (Lüning, 1990), competição, introdução de espécies exóticas (Orth et al., 2006), herbivoria e impactos antrópicos (Burkholder et al., 2007), afetam a abundância das espécies de macroalgas. Dessa forma, o conjunto de fatores abióticos e bióticos (incluindo impactos antropogênicos) conseguem influenciar as taxas de crescimento das macroalgas, de forma a alterar suas abundâncias e dinâmicas populacionais (Adey, 1998).

\section{Estado de conservação local e biomonitoramento}

Trabalhos realizados em ambientes recifais intertidais próximos (Sousa e Concentino, 2004, Vasconcelos, 2016) e no próprio recife de Formosa (Máximo, 2015) verificaram a ocorrência de taxa característicos de áreas submetidas a impactos antrópicos, como o gênero Ulva, por exemplo. Littler e Littler (1980) e Teichberg et al. (2010) classificam as espécies de Ulva como oportunistas e excelentes indicadoras de eutrofização. No presente trabalho não foram amostradas espécies de Ulva, nem espécies exóticas ao litoral nordestino, o que corrobora a ideia de boa qualidade ambiental do recife de Formosa, porém destaca-se a necessidade de atenção ao desenvolvimento desse grupo de espécies em programas de monitoramento no recife.

Atualmente, várias propostas de biomonitoramento utilizam-se da metodologia de análise "top-down", a qual avalia, em nível macro, os impactos ambientais com base na alteração da organização estrutural e funcional das comunidades biológicas. Essa metodologia se provou viável em muitos casos e representam o caminho mais rápido e prático para o manejo dos ecossistemas aquáticos (Buss et al., 2003). Análise das abundâncias relativas de espécies bioindicadoras é um importante fator a ser considerado em propostas de biomonitoramento com metodologia de análise "top-down", embora discuta-se a influência da "ausência" de uma espécie (Cairns Jr. e Pratt, 1993).

A composição de comunidades macrofitobênticas envolve espécies com diferentes níveis de sensibilidade a distúrbios e variações temporais nos níveis de abundância relativa (Areces Mallea et al., 2016), no qual o conhecimento desses aspectos constitui a base para formulação de propostas de biomonitoramento da qualidade ecossistêmica (Silva et al., 2008).

\section{Conclusão}

A frequência de ocorrência ( $\left.F^{\prime}\right)$ das espécies macrofitobênticas do ambiente recifal de Formosa apresenta variação temporal, porém não foram detectadas variações temporais nas condições ambientais, o que pode explicar a perenidade das espécies do Grupo 1 e indicar que a flutuação de F' das espécies do Grupo 2 está ligada a outros fatores.

0 ambiental recifal da Praia de Formosa representa uma área com boa qualidade ambiental, não estando submetidos a impactos antrópicos 
significativos e podendo representar uma Área Controle para avaliações do impacto turístico sobre os recifes costeiros da Paraíba, principalmente sobre o adjacente ambiente recifal protegido pelo Parque Estadual Marinho de Areia Vermelha.

A proposta de biomonitoramento aqui desenvolvida objetiva contribuir com a manutenção da qualidade ambiental do recife de Formosa-PB, fornecendo a gestão uma ferramenta para avaliação do impacto urbano sobre a comunidade macrofitobêntica, visando ao desenvolvimento sustentável.

\section{Conflito de interesses}

Os autores declaram não haver conflito de interesses.

\section{Referências}

Adey, W. H. Coral reefs: Algal structured and mediated ecosystems in shallow, turbulent, alkaline waters. Journal of Phycology, v. 34, p. 393-406, 1998. https://doi.org/10.1046/ j.1529-8817.1998.340393.x

Areces Mallea, A. J.; Cocentino, A. L. M.; Reis, T. N. V.; Vasconcelos, E. R. T. P. P.; GuimarãesBarros, N. C.; Fujii, M. T. Las macroalgas como bioindicadoras da calidad ambiental y cambios climáticos. Guia prática. Brazilian Journal of Ecology, v. Especial, p. 1-64, 2015. Areces Mallea, A. J.; González-Sánches, P.; Guerra, J. B. Relative abundance of benthic macroalgae (RAM) as a tool in rapid environmental quality assessment. Serie Oceanológica, $\quad$ n. 15, p. 58-73, 2016. Disponível em: <http://oceanologia.red ciencia.cu/articulos/Abundancia\%20relativa. pdf>. Acesso em: 09 maio 2017.

Azevedo, C. A. A.; Carneiro, M. A. A.; Oliveira, S. R.; Marinho-Soriano, E. Macroalgae as an indicator of the environmental health of the Pirangi reefs, Rio Grande do Norte, Brazil. Revista Brasileira de Farmacognosia, v. 21, p. 323-328, 2011. https://doi.org/10.1590/ S0102-695X2011005000071

Bruno, J. F.; Precht, W. F.; Vroom, P. S.; Aronson, R. B. Coral reef baselines: How much macroalgae is natural? Marine Pollution Bulletin, v. 80, p.24-29, 2014. https://doi.org/10.1016/j.marpolbul.2014.0 1.010

Burkholder, J. M.; Tomasko, D. A.; Touchette, B. W. Seagrasses and eutrophication. Journal of Experimental Marine Biology and $\begin{array}{lll}\text { Ecology, } & \text { v. } 350, \quad \text { p. } 46-72, & 2007 .\end{array}$ https://doi.org/10.1016/j.jembe.2007.06.02 4

Buss, D. F.; Baptista, D. F; Nessimian, J. L. Conceptual basis for the application of biomonitoring on stream water quality programs. Caderno de Saúde Pública, v. 19, n. 2 , p. $465-473,2003$. https://doi.org/ 10.1590/S0102-311X2003000200013

Cabedelo. Prefeitura de Cabedelo. Projeto Orla. 2004. Disponível em: <http://www.mma.gov.br/estruturas/orla/_ arquivos/cabedelovf1_11.pdf>. Acesso em: 09 maio 2017.

Cairns Jr., J.; McCormick, P. V.; Niederlehner B. R. A proposal framework for developing indicators of ecosystem health. Hydrobiologia, v. 263, p. 1-44, 1993. https://doi.org/10.1007/BF00006084

Conde. Prefeitura do Conde. Plano de gestão integrada da orla marítima do Município de Conde. 2008. Disponível em: <http://www.mma.gov.br/estruturas/orla/_ arquivos/pgi_orla_condepb_aprovado_ctepb_ 11.pdf>. Acesso em: 04 maio 2017.

Costa, C. F.; Sassi, R.; Costa, M. A. J.; Brito, A. C. L. Recifes costeiros da Paraíba, Brasil: usos, impactos e necessidades de manejo no contexto da sustentabilidade. Gaia Scientia, v. 1, n. 1, p. 37-45, 2007. Disponível em: <http://www.periodicos.ufpb.br/index.php/ gaia/article/view/2226>. Acesso em: 09 maio 2017.

Costa, R. J. Impactos ambientais do turismo/lazer no recife de Areia Vermelha: a metodologia de limites de mudanças aceitáveis. João Pessoa: Universidade Federal da Paraíba, 2016. (Dissertação de mestrado).

Davison, I. R.; Pearson, G. A. Stress tolerance in intertidal seaweeds. Journal of Phycology, v. 32, p.197-211, 1996. https://doi.org/10.1111/j.0022-3646.1996. 00197.x

Dayton, P. K.; Tegner, M. J.; Edwards, P. B.; Riser, K. L. Sliding baselines, ghosts, and reduced expectations in kelp forest communities. Ecological Applications, v. 8, n. 2, p. 309-322, 1998. https://doi.org/ $10.2307 / 2641070$ 
Dhargalkar, V. K.; Komarpant, D. S. Impact of sewage on the distribution, abundance and community structure of rocky intertidal macroalgae of the Colaba Coast, Mumbai, India. Seaweed Research and Utilization, v. 25 , n. $1 / 2$, p. $27-36,2003$. Disponível em: <http://drs.nio.org/drs/handle/2264/443>. Acesso em: 09 maio 2017.

Estes, J. A.; Terborgh, J.; Brashares, J. S.; Power, M. E.; Berger, J.; Bond, W. J.; Carpenter, S. R.; Essington, T. E.; Holt, R. D.; Jackson, J. B. C.; Marquis, R. J.; Oksanen, L.; Oksanen T.; Paine, R. T.; Rippie, W. J.; Sandin, S. A.; Scheffer, M.; Schoener, T. W.; Shurin, J. B.; Sinclair, A. R. E.; Soulé M. E.; Virtanen, R.; Wardle, D. A. Trophic downgrading of Planet Earth. Science, v. 333, p. 301-306, 2011. https://doi.org/10.1126/science.1205106

Feliciano, M. L. M.; Melo, R. B. Atlas do Estado da Paraíba: informação para gestão do patrimônio natural. 1. ed. João Pessoa: Seplan/Ideme, 2003.

Fong, P.; Boyer, K. E.; Kamer, K.; Boyle, K. A. Influence of initial tissue nutrient status of tropical marine algae on response to nitrogen and phosphorus additions. Marine Ecology Progress Series, v. 262, p. 111-123, 2003. https://doi.org/10.3354/meps 262111

Fontana, C.; Sevegnani, L. Quais são as espécies arbóreas comuns da floresta estacional decidual em Santa Catarina? Revista de Estudos Ambientais, v. 14, p. 7488, 2012. https://doi.org/10.7867/19831501.2012v14n1p74-88

Francini-Filho, R.B.; Moura, R.L. Evidence for spillover of reef fishes from a no-take marine reserve: an evaluation using the before-after control-impact (BACI) approach. Fisheries Research, v. 93, p. 346-356, 2008. https://doi.org/10.1016/j.fishres.2008.06.01 1

Freire, A. R. S.; Moura, E. A.; Pereira, D. C.; Marinho-Soriano, E. Efeito dos parâmetros ambientais sobre o crescimento e a biomassa de Gelidella acerosa cultivada em viveiros de camarão. Revista Brasileira de Biociências, v. 5, p. 804-806, 2007. Disponível em: <http://www.ufrgs.br/seerbio/ojs/index.ph $\mathrm{p} / \mathrm{rbb} /$ article/view/679/569>. Acesso em: 09 maio 2017.

Galvão, T. A.; Nolasco, M. C. Urbanization and coral reefs in Guarajuba Beach, North Coast of Bahia, Brazil. Ocean \& Coastal Management, v. 77, p. 50-58, 2013. https://doi.org/10.1016/j.ocecoaman.2012.0 3.013

Gaston, K. J. Rarity. Londres: Chapman \& Hall, 1994.

Gorostiaga, J. M.; Díez, I. Changes in the sublittoral benthic marine macroalgae in the polluted area of Abra de Bilbao and proximal coast (Northern Spain). Marine Ecology Progress Series, v. 130, p. 157-167, 1996. https://doi.org/10.3354/meps130157

Governo do Estado da Paraíba. Atlas Geográfico do Estado da Paraíba. João Pessoa: Grafset, 1985.

Guerra-García, J. M.; Cabezas, P.; BaezaRojano, E.; García-Gómez, J.C. Spatial patterns and seasonal fluctuations of intertidal macroalgal assemblages from Tarifa Island, Southern Spain: Relationship with associated Crustacea. Journal of the Marine Biological Association of the United Kingdom, v. 91, p. 107-116, 2011. https://doi.org/10.1017/S00253154100012 19

Guiry, M. D.; Guiry, G. M. AlgaeBase. Worldwide electronic publication, National University of Ireland, Galway. 2018.

Horta, P. A.; Amâncio, E.; Coimbra, C. S.; Oliveira, E. C. Considerações sobre a distribuição e origem da flora de macroalgas marinhas brasileiras. Hoehnea, v. 28, n. 3, p. 243-265, 2001.

João Pessoa. Prefeitura de João Pessoa. Projeto de Gestão Integrada da Orla Marítima Projeto Orla. 2004.

Köppen, W. Versuch einer Klassifikation der Klimate, vorzugsweise nach ihren Beziehungen zur Pflanzenwelt. Geographische Zeitschrift, v. 6, n. 11, p.593-611, 1900. Disponível em: <http://www.jstor.org/stable/27803924>. Acesso em: 09 maio 2017.

Kunin, W. E.; Gaston, K. J. The biology of rarity: Patterns, causes and consequences. Trends in Ecology and Evolution, v. 8, n. 8, p. 298-301, 1993. https://doi.org/10.1016/ 0169-5347(93)90259-R

Littler, M. M.; Littler, D. S. The evolution of thallus form and survival strategies in benthic marine macroalgae: Field and laboratory test of a functional form model. American Naturalist, v. 116, n. 1, p. 25-44, 1980. Disponível em: <http://www.jstor.org/ stable/2460708>. Acesso em: 09 maio 2017. 
Littler, M. M.; Littler, D. S.; Brooks, B. L. Harmful algae on tropical coral reefs: Bottom-up eutrophication and top-down herbivory. Harmful Algae, v. 5, p. 565-585, 2006. https://doi.org/10.1016/j.hal.2005. 11.003

Lourenço, L. J. S. Proposta de zoneamento e capacidade de carga para o Parque Estadual Marinho de Areia Vermelha. João Pessoa: Universidade Federal da Paraíba, 2010. (Dissertação de mestrado).

Lourenço, L. J. S.; Crispim, M. C.; Eloy, C. C. Caracterização do Parque Estadual Marinho de Areia Vermelha, Cabedelo, PB, baseado na diversidade e abundância dos cnidários da Classe Anthozoa, como subsídio para o zoneamento ecológico econômico. Gaia

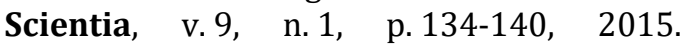
Disponível em: <http://www.periodicos. ufpb.br/index.php/gaia/article/view/24077 >. Acesso em: 09 maio 2017.

Lüning, K. Seaweeds, their environment, Biogeography and Ecophysiology. New York: John Wiley \& Sons, 1990.

Mataraca. Prefeitura de Mataraca. Plano de Gestão Integrada da Orla Marítima do Município de Mataraca - Paraíba. 2010. Disponível em: <http://www.mma.gov.br/ estruturas/orla/_arquivos/pgi_orla_mataraca _pre_cte_11.pdf>. Acesso em: 08 Maio 2017.

Máximo, L. N. Estrutura e dinâmica de populações e comunidades de macroalgas em ambientes recifais da Paraíba. Paraíba: Universidade Federal da Paraíba, 2015. (Dissertação de Mestrado).

McKinney, M. L. Urbanization, biodiversity, and conservation. BioScience, v. 52, n. 10, p. 883-890, 2002. https://doi.org/10.1641/ 0006-3568(2002)052[0883:UBAC]2.0.C0;2

Melo, R. S.; Crispim, M. C.; Viana, E. R.; Lins, R. P. Planejamento turístico e zoneamento ambiental: um estudo de caso nos ambientes recifais das praias do Seixas, Penha e Arraial (Paraíba, Brasil). Caderno Virtual de Turismo, v. 8, n. 2, p. 23-33, 2008. Disponível em: <http://www.ivt.coppe.ufrj.br/caderno/ index.php/caderno/article/viewFile/223/17 1>. Acesso em: 09 maio 2017.

Mikkelsen, P. M.; Cracraft, J. Marine biodiversity and the need for systematic inventories. Bulletin of Marine Science, v. 69, p. 525-534, 2001. Disponível em: <http://www.ingentaconnect.com/content/u mrsmas/bullmar/2001/00000069/0000000 2/art00025>. Acesso em: 09 maio 2017.
MMA - Ministério do Meio Ambiente. Consultas por UC's. 2017. Disponível em: <http://www.mma.gov.br/areas-protegidas/ cadastro-nacional-de-ucs/consulta-por-uc>. Acesso em: 09 Maio 2017.

Moberg, F.; Folke, C. Ecological goods and services of coral reef ecosystems. Ecological

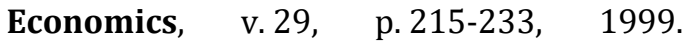
https://doi.org/10.1016/S0921-8009(99) 00009-9

Moreira, A. R.; Armenteros, M.; Batista, G. M.; Leon, A. R.; Cabrera, R.; Castellanos, M. E.; Caravaca. A. M.; Suárez, A. M. Variation of macroalgae biomass in Cienfuegos Bay, Cuba. Revista de Investigaciones Mariñas, v. 27, p.3-12, 2006. Disponível em: <http://www.rim.uh.cu/index.php/RIM/arti cle/view/28/28>. Acesso em: 09 maio 2017.

Ocean Color. NASA Goddard Space Flight Center. Ocean Ecology Laboratory. Ocean Biology Processing Group. Sea-viewing Wide Field-of-view Sensor (SeaWiFS) Ocean Color Data, NASA OB.DAAC. 2016. https://doi.org/10.5067/ORBVIEW-

2/SEAWIFS_OC.2014.0

Oigman-Pszczol, S. S.; Creed, J. C. Can patterns in benthic communities be explained by an environmental pressure index? Marine Pollution Bulletin, v. 62, p. 2181-2189, 2011. https://doi.org/10.1016/j.marpolbul. 2011.07.001

Orth, R. J.; Carruthers, T. J B.; Dennison, W. C.; Duarte, C. M.; Fourqurean, J. W.; Heck, K. L.; Hughes, R.; Kendrick, G. A.; Kenworthy, W. J.; Olyarnik, S.; Short, F. T.; Waycott, M.; Williams, S. L. A global crisis for seagrass ecosystems. BioScience, v. 56, p. 987-996, 2006. https://doi.org/10.1641/0006-3568 (2006)56[987:AGCFSE]2.0.C0;2

Pereira, S. M. B.; Oliveira-Carvalho, M. F.; Angeiras, J. A. P.; Oliveira, N. M. B.; Torres, J.; Gestinari, L. M. S.; Bandeira-Pedrosa, M. E.; Cocentino, A. L. M.; Santos, M. D.; Nascimento, P. R. F.; Cavalcanti, D. R. Algas marinhas bentônicas do Estado de Pernambuco. In: Tabarelli, M.; Silva, J. M. (Eds.). Diagnóstico da biodiversidade de Pernambuco. Recife: Massangana, Secretaria de Ciência, Tecnologia e Meio Ambiente, 2002. p. 97-124. Pinedo, S.; García, M.; Satta, M. P.; de Torres, M.; Ballesteros, E. Rocky-shore communities as indicators of water quality: A case study in the Northwestern Mediterranean. Marine Pollution Bulletin, v. 55, p. 126-135, 2007. 
https://doi.org/10.1016/j.marpolbul.2006.0 8.044

Pitimbu. Prefeitura de Pitimbu. Plano de Gestão Integrada da Orla de Pitimbu. 2015. Disponível em: <http://www.pitimbu. pb.gov.br/_upload/publicacoes/pub1501161 02156.pdf>. Acesso em: 09 maio 2017.

Rabinowitz, D.; Cairns, S.; Dillon, T. Seven forms of rarity and their frequency in the flora of the British Isles. In: Soulé M. E. (Ed.). Conservation Biology: The science of scarcity and diversity. USA: University of Michigan, 1986. p. 182-204.

Rao, V.; Lima, M. C.; Franchito, S. Seasonal and interannual variations of rainfall over Eastern Northeast Brazil. Journal of Climate, v. 6, p. 1754-1763, 1993. https://doi.org/ 10.1175/1520-0442(1993)006<1754:

SAIVOR $>2.0 . \mathrm{CO} ; 2$

Sarmento, V.; Santos, P. Trampling on coral reefs: Tourism effects on harpacticoid copepods. Coral Reefs, v. 31, p. 135-146, 2012. https://doi.org/10.1007/s00338011-0827-2

Scarano, F. R. Prioridades para conservação: a linha tênue que separa teorias e dogmas. In: Rocha, C. F. D.; Bergallo, H. G.; Sluys, M. V.; Alves, M. A. S. Biologia da Conservação: essências. São Carlos: RiMa, 2006. p. 23-39.

Scherner, F.; Barufi, J. B.; Horta, P. A. Photosynthetic response of two seaweeds species along an urban pollution gradient: Evidence of selection of pollution-tolerant species. Marine Pollution Bulletin, v. 64, p. 2380-2390, 2012. https://doi.org/10.1016/ j.marpolbul.2012.08.012

Silva, I. B.; Fujii, M. T.; Marinho-Soriano, E. Influence of tourist activity on the diversity of seaweed from reefs in Maracajaú, Atlantic Ocean, Northeast Brazil. Revista Brasileira de Farmacognosia, v. 22, p. 889-893, 2012. https://doi.org/10.1590/S0102-695X2012 005000078

Silva, M. B. Dinâmica dos padrões sucessionais do macrofitobentos em áreas marinhas sob diferentes regimes de proteção. João Pessoa: Universidade Federal da Paraíba, 2013. (Dissertação de mestrado).
Silva, M. S. G. M.; Queiroz, J. F.; TrivinhoStrixino, S. Indicadores biológicos de qualidade. In: Silva, M. S. G. M.; Queiroz, J. F.; Trivinho-Strixino, S. (Eds.). Organismos bentônicos: biomonitoramento de qualidade de água. São Paulo: Embrapa Meio Ambiente, 2008. p. 26-35.

Sousa, G. S.; Cocentino, A. L. M. Macroalgas como indicadoras da qualidade ambiental. Tropical Oceanography, v. 32, p. 1-22. 2004. Disponível em: <https://periodicos.ufpe.br/ revistas/TROPICALOCEANOGRAPHY/article/ view/5030/4314>. Acesso em: 09 maio 2017.

Souza, A. T.; Ilarri, M. I.; Medeiros, P. M.; Grempel, R. G.; Rosa, R. S.; Sampaio, C. S. Fishes (Elasmobranchii and Actinopterygii) of Picãozinho Reef, Northeastern Brazil, with notes on their conservation status. Zootaxa, v. 1608, n. 1, p. 11-19, 2007.

Steneck, R. S.; Dethier, M. N. A functional group approach to the structure of algal dominated communties. Oikos, v. 69, p. 476498, 1994. Disponível em: <http://www.aoml.noaa.gov/general/lib/CR EWS/Cleo/St.\%20Croix/salt_river84.pdf>. Acesso em: 09 maio 2017.

SUDEMA - Superintendência de Administração do Meio Ambiente. Quem Somos. 2017. Disponível em: <http://sudema.pb.gov.br/institucional>. Acesso em: 05 maio 2017.

Teichberg, M.; Fox, S. E.; Olsen, Y. S.; Valiela, I.; Martinettos, P.; Iribarnes, O.; Muto, E. Y.; Petti, M. A. V.; Corbisier, T. N.; Soto-Jimenez, M.; Paes-Osuna, F.; Castro, P.; Freitas, H.; Zitelli, A.; Cardinaletti, M.; Tagliapietra, D. Eutrophication and macroalgal blooms in temperate and tropical coastal waters: Nutrient enrichment experiments with Ulva spp. Global Change Biology, v. 16, n. 9, p. 2624-2637, 2010. https://doi.org/ 10.1111/j.1365-2486.2009.02108.x

Vasconcelos, E. R. T. P. P.; Reis, T. N. V.; Guimarães-Barros, N. C.; Bernardi, J.; Areces Mallea, A. J.; Cocentino, A. L. M.; Fujii, M. T. Padrão espacial da comunidade de macroalgas de mesolitoral em ambiente 
recifal do nordeste brasileiro. Tropical Oceanography, v. 41, n. 1/2, p. 84-92, 2013. https://doi.org/10.5914/tropocean.v41i12.5416

Vasconcelos, E. R. T.P.P. Macroalgas marinhas bentônicas como ferramenta de avaliação do estado de conservação dos ambientes recifais em Pernambuco. Recife: Universidade Federal de Pernambuco, 2016. (Tese de doutorado). 